\title{
The evolution of a highly variable sex chromosome in Gehyra purpurascens (Gekkonidae)
}

\section{Moritz}

Department of Population Biology, Research School of Biological Sciences, The Australian National University Canberra, A.C.T., Australia; present address: Division of Biological Sciences, natural science building, University of Michigan, MI 48109, USA

\begin{abstract}
A karyotypic survey of the gekkonid lizard Gehyra purpurascens revealed a distinctive sex chromosome system. G-banding showed that the $\mathrm{Z}$ Chromosome of males is derived from a tandem fusion of two acrocentric chromosomes of a presumed ancestral Gehyra with $2 n=44$. Through the application of $\mathrm{G}-; \mathrm{N}$ - and C-banding, a total of six morphs of the $\mathrm{W}$ chromosome were identified. These differ by paracentric and pericentric inversions and, in one case, by a centric shift. The possible reasons for such extensive variation in the $\mathrm{W}$ chromosome are considered, and it is suggested that increased mutability of the W chromosome may be a causal factor. In contrast to earlier speculations, this example demonstrates that sex chromosomes can evolve without significant changes in the amount of C-band heterochromatin.
\end{abstract}

\section{Introduction}

The detailed mechanism responsible for the initial stages of the evolution of cytogenetically recognisable sex chromosomes in vertebrates remain unresolved. It is generally agreed, however, that the accumulation of sex-determining genes on one of a pair of developing sex chromosomes requires some form of restriction on their free recombination.

Two major hypotheses have been advanced to explain this primary stage of sex chromosome differentiation. First, Ohno (1967) stressed the role of structural rearrangements in restricting recombination between the presumptive heteromorphic elements. Thus while the initial step in the isolation of sex chromosomes might be related to either the gonadal environment (Ohno 1967) or sex-specific genic effects (Darlington 1958) a more stable differential segment would be created by structural divergence between the homologues.

Second, heterochromatinisation of the $\mathrm{Y}$ or W, by means of the amplification and spread of a sex-specific satellite DNA, has been offered as an alternative mechanism for restricting recombination between the sex chromosomes (Ray Chaudhuri 1971; Singh et al. 1976, 1980). According to this hypothesis heterochromatinisation represents the first step in the differentiation of sex chromosomes and the accumulation of structural rearrangements may then follow as a secondary phenomenon.

Singh et al. $(1976,1980)$ and more recently Schempp and Schmid (1981) have proposed that the repetitive DNA of sex chromosomes restricts recombination by virtue of its late replication. However, there is no evidence that this asynchronous replication, which has been observed only at mitosis, directly interferes with the synapsis of homologous chromosomes at zygotene. Further, although highly repetitive DNA when present as $\mathrm{C}$-band heterochromatin may restrict recombination (John and Miklos 1979) this effect has not been demonstrated for repetitive DNA outside C-bands. On this basis the satellite DNA model for the evolution of sex chromosomes should be restricted to organisms in which the sex-specific satellites are present as C-band positive heterochromatin.

Mengden (1981) pointed out that there appear to be multiple mechanisms for the origin of sex chromosomes in vertebrates. Thus examples exist where structural rearrangements result in a heteromorphic element with no change in $\mathrm{C}$-band heterochromatin content between two homologues. In contrast, there are also cases of morphologically indistinguishable sex chromosomes but with different amounts of C-band material.

The lower vertebrates, and in particular the lizards, provide excellent material in which to examine these hypotheses. Amongst lizards there are demonstrated examples of female (ZW) and male (XY) heterogamety, which suggest a polyphyletic origin for sex chromosomes in this group. Further, in several cases where intraspecific variation occurs, the evolution of cytologically distinguishable sex chromosomes appears to be relatively recent (King 1977; Bull 1980; Bickham in press).

In this respect members of the Gekkonidae are especially interesting. Three cases of intraspecific variation for ZW sex chromosome differentiation have been described in this family. They involve: (1) interracial variation in Phyllodactylus marmoratus for a pericentric inversion polymorphism of chromosome 4 (King and Rofe 1976), (2) an amplification of $\mathrm{C}$-band heterochromatin in the short arm of chromosome 1 detected in certain populations of a chromosomal race of Gehyra australis (King 1977), and (3) interpopulation variation for a change in the location of a $\mathrm{C}$-band that defines the $\mathrm{W}$ chromosome in Heteronotia binoei (Moritz 1984).

This paper concerns the evolution of a highly variable $\mathrm{W}$ chromosome in the gekkonid Gehyra purpurascens. Although only approximately half of the species distribution has been sampled, six morphs of the $\mathrm{W}$ chromosome have already been recognized. A detailed cytogenetic analysis of these, employing $\mathrm{G}-, \mathrm{C}-$, and $\mathrm{N}$-banding and silver staining, has demonstrated that highly derived heteromorphic sex 


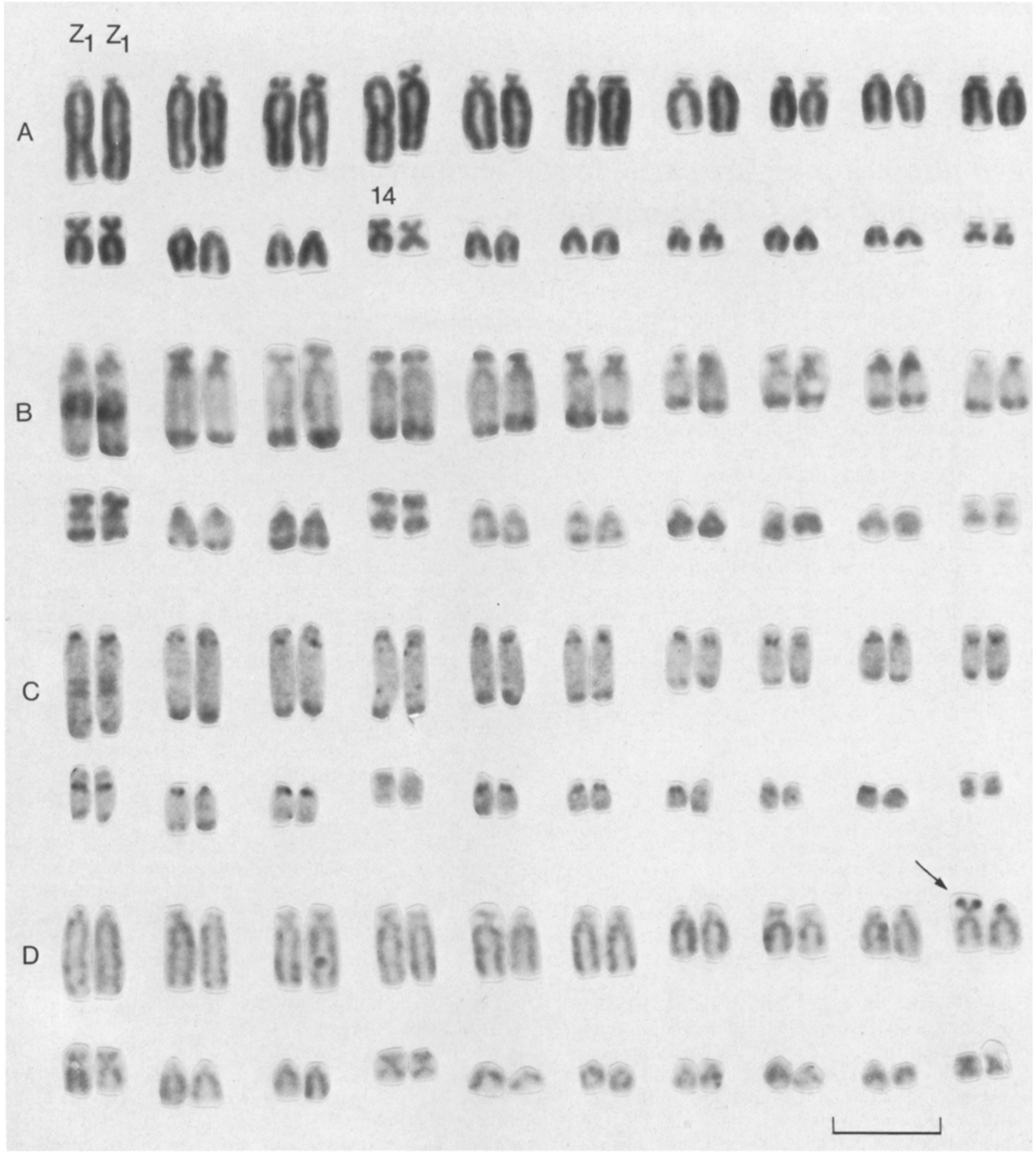

Fig. 1. A-D Karyotype of Gehyra purpurascens. A Conventionally stained. B N-banded, C C-banded. D Silver stained. These karyotypes are all from males that were homozygous for the $Z_{1}$ chromosome (pair 1 ). The standard karyotype (A) is also heterozygous for a pericentric rearrangement of chromosome 4 which is the only autosomal polymorphism observed in this species. Arrow in $\mathbf{D}$ indicates nucleolus organising region. Bar represents $8 \mu \mathrm{m}$

chromosomes can evolve by structural rearrangements without quantitative changes in C-band heterochromatin.

\section{Materials and methods}

The localities from which the 72 specimens examined were collected are given in Table 1 . The methods for obtaining mitotic chromosomes from short-term leucocyte culture and for C-banding are given elsewhere (Moritz 1984). Airdried meiotic preparations were produced by the method of King and Rofe (1976) except that the animais were not treated with colchicine prior to being killed.

G-banding was obtained by modification of the trypsin treatment technique (Leversha et al. 1980) and the silver staining method used is that of Olert (1979). The N-banding method is modified from Gerlach (1977). 


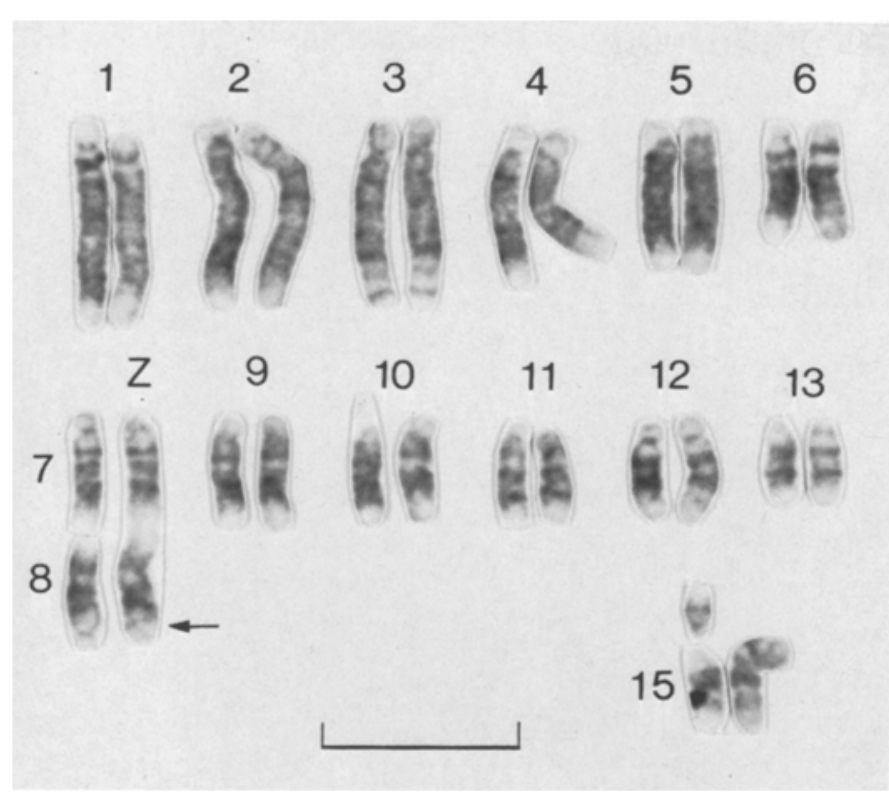

Fig. 2. Haploid G-band comparison of the first 13 pairs of chromosomes of the proposed ancestral Gehyra with $2 n=44$ (represented by central Australian $G$. nana) (left chromosome of pair) and $G$. purpurascens with $2 n=40$ (right chromosome of pair.) The chro mosome arms of $G$. purpurascens are numbered according to their position in the ancestral karyotype and not in the decreasing size relationship shown in Figure $1 \mathrm{~A}$. At the bottom right, the second fusion, which involves the ancestral pair 15 and an unidentified small acrocentric of the $2 n=44$ race, is also shown. This submetacentric chromosome is the eleventh in the karyotype of G. purpurascens (see Fig. $1 \mathrm{~A}$ ). The $\mathrm{Z}$ chromosome of $G$. purpurascens is derived from a tandem fusion of the distal telomeres of chromosomes 7 and 8 from the ancestral $2 n=44$ race (compare Fig. 4A). Also note the presence of a faint $G$-band on the $Z$ (arrow), which corre sponds to the original position of the chromosome 8 centromere. Bar represents $8 \mu \mathrm{m}$

\section{Results}

\section{Derivation of the karyotype}

Gehyra purpurascens is a derived member of the Gehyra variegata-punctata species complex. The ancestral condition in this complex is thought to be $2 n=44$ with a metacentric pair 14 and the nucleolar organizing region (NOR) located on pair 10 (King 1979; Moritz, in preparation). The conventionally stained karyotype of a male $G$. purpurascens, $2 n=40$, is shown in Figure $1 \mathrm{~A}$. The sex chromosomes (pair 1) are homomorphic $\left(Z_{1} Z_{1}\right)$ in this male and pair 14 is submetacentric, which is common to most other members of this species complex.

The derivation of the $2 n=40$ condition from a presumed $2 n=44$ ancestral karyotype by two fusion events has been demonstrated by a G-banding comparison of the $2 n=44$ race and $G$. purpurascens. For this comparison the $2 n=44$ condition was represented by $G$. nana from central Australia, though it is worth emphasizing that the G-band pattern of the geographically and taxonomically diverse $2 n=44$ forms of Australian Gehyra is highly conserved (Moritz, in preparation). Figure 2 clearly demonstrates that the $Z$ chromosome of $G$. purpurascens is derived from the ancestral condition by a telomere-to-telomere tandem fusion of chromosomes 7 and 8 . In the terminology of $\mathrm{Hsu}$ et al. (1975) this can be described as K7T-T8(k). It should be noted that there does not appear to be any loss of chromatin from the centromeric region of chromosome 8 .

The second fusion involves pair 15 and a small acrocentric element from the $2 n=44$ karyotype to produce the submetacentric pair 11 of G. purpurascens (Fig. 2).

When metaphase cells were N-banded, the only Giemsastained material was located at the site of the nucleolar organizing region (NOR). However, with a milder treatment the telomeric region of most chromosomes stained intensely, as did the interstitial band on chromosome 1, the proximal bands on chromosomes 10 and 11, and the short arms of chromosome 11 (Fig. $1 \mathrm{~B}$ ). The interstitial N-band of pair 1 in $G$. purpurascens presumably reflects the fusion of the distal N-positive regions of the ancestral chromosomes 7 and 8. By comparison, the C-banding technique (Fig. 1C) repeatedly showed intense banding of the centromeric region only. Under these conditions the strong interstitial and telomeric $\mathrm{N}$-banding regions exhibit grey $\mathrm{C}$-bands. Additionally the strongly $\mathrm{N}$-banded short arm of chromosome 11 shows no $C$-band reaction whatsoever. This comparison attests to the heterogeneous nature of heterochromatin in this species, as has also been demonstrated for the $W$ chromosome of snakes and birds (Mengden 1981).

The silver staining method was used to demonstrate that the interstitial $\mathrm{N}$ band on the $\mathrm{Z}$ chromosome was not an active NOR. In fact the only active NOR in $G$. purpurascens is located terminally on the short arms of pair 10 (Fig. 1D).

\section{Sex chromosome variation}

G. purpurascens exhibits a level of intrachromosomal rearrangement within the sex chromosomes greater than that shown by any other vertebrate. This involves primarily the $\mathrm{W}$ chromosome and results in both intra- and interpopulation variation (Table 1 ). The variants were initially identified by $\mathrm{N}$-banding; however, to resolve the precise nature of the rearrangements involved, a comparative $\mathrm{G}, \mathrm{C}$-, and $\mathrm{N}$-banding analysis was employed (Fig. $3 \mathrm{~A}-\mathrm{D}$ ).

With one exception, all 42 males analysed were homozygous for the acrocentric $Z$ chromosome $\left(Z_{1} Z_{1}\right)$. One male from Curtin Springs was heterozygous for a metacentric $Z_{2}$ variant (Fig. 3), which is derived from the $Z_{1}$ morph by a large pericentric rearrangement.

Among the 30 females examined, six distinctive morphs of the $\mathrm{W}$ chromosome were evident $\left(\mathrm{W}_{\mathrm{a}}-\mathrm{W}_{\mathrm{f}}\right.$, Fig. 3). While the gross morphology of some of these is superficially similar (cf. $W_{a}$ and $W_{c} ; W_{b}$ and $W_{f}$ ), banding analysis has demonstrated that they are strongly divergent. A comparison of the $\mathrm{C}$ - and N-banding patterns of these morphs is particularly revealing. As already discussed the strongly $\mathrm{N}$-banded regions exhibit grey C-banding. In some cases, however, (e.g. $W_{c}$, Fig. 3) a strong C-band, which is also $\mathrm{G}$-band positive, is evident in the middle of this region.

Three to five G-banded prometaphase and early metaphase plates of each W morph were analysed to determine the precise nature of the rearrangements involved. The individual bands were identified relative to the banding pattern of the ancestral chromosomes 7 and 8 , the presumed progenitors of the $Z$ chromosome.

The two narrow bands located in the proximal half of chromosome 7 are designated $7-1$ and $7-2$, while the more distal broad band is denoted 7-3 (Fig. 4A). In some exceptional preparations, 7-3 appears as two discrete bands $\left(W_{d}\right.$, Fig. 3). The three bands of chromosome 8 are of similar 
Table 1. Sex chromosome genotypes observed in $72 \mathrm{G}$. purpurascens from the 20 central Australian localities shown in Figure 5

\begin{tabular}{|c|c|c|c|c|c|c|c|c|c|}
\hline \multirow[t]{3}{*}{ Locality } & & \multicolumn{8}{|c|}{ Sex chromosome genotypes } \\
\hline & & \multicolumn{2}{|l|}{ Male } & \multicolumn{6}{|c|}{ Female } \\
\hline & & $Z_{1} Z_{1}$ & $\mathrm{Z}_{1} \mathrm{Z}_{2}$ & $\mathrm{Z}_{1} \mathrm{~W}_{\mathrm{a}}$ & $\mathrm{Z}_{1} \mathrm{~W}_{\mathrm{b}}$ & $\mathrm{Z}_{\mathrm{l}} \mathrm{W}_{\mathrm{c}}$ & $\mathrm{Z}_{\mathrm{i}} \mathrm{W}_{\mathrm{d}}$ & $\mathrm{Z}_{\mathrm{j}} \mathrm{W}_{\mathrm{e}}$ & $\mathrm{Z}_{1} \mathrm{~W}_{\mathrm{f}}$ \\
\hline 1. McDouall Peak H.S. & S.A. ${ }^{a}$ & & & & & & 1 & & \\
\hline 2. Cordillo Downs H.S. & S.A. & 1 & & & & & & & \\
\hline 3. Kulgera & N.T. & 7 & & & & 2 & & & \\
\hline 4. Finke & N.T. & 1 & & & & & & & \\
\hline 5. New Crown H.S. & N.T. & 2 & & & & 1 & & & \\
\hline 6. Old Andado H.S. & N.T. & 1 & & & & & 1 & & \\
\hline 7. Lilla Ck. H.S. & N.T. & & & & & & 1 & & \\
\hline 8. Mt Ebenezer & N.T. & 2 & & & 2 & 1 & & & \\
\hline 9. Curtin Springs H.S. & N.T. & 4 & 1 & 2 & & & & & \\
\hline 10. Connellan Airport & N.T. & 1 & & 1 & & & & & \\
\hline 11. Maryvale H.S. & N.T. & 1 & & & & & & & \\
\hline 12. Deep Well H.S. & N.T. & 1 & & & & & & & \\
\hline 13. Ross River H.S. & N.T. & 1 & & 2 & & & & & \\
\hline 14. Undoolya H.S. & N.T. & 1 & & & & & & & \\
\hline 15. Rabbit Flat & N.T. & 1 & & & & & & 1 & \\
\hline 16. Ti Tree & N.T. & 4 & & 8 & & & & & \\
\hline 17. Giles & W.A. & 8 & & 6 & & & & & \\
\hline 18. Blackstone Ra. & W.A. & 1 & & & & & & & \\
\hline 19. Wingelinna & W.A. & 1 & & & & & & & 1 \\
\hline 20. Notabilis Hill & W.A. & 3 & & & & & & & \\
\hline
\end{tabular}

a S.A. indicates South Australia; N.T., Northern Territory; and W.A., West Australia.

width but can be discriminated by their relative separation, bands $8-1$ and $8-2$ being close together with a wider Gnegative gap to band $8-3$ (Fig. $4 \mathrm{~A}$ ).

The analysis was facilitated by a concurrent consideration of the N-band patterns. Since the proximal regions of chromosomes 7 and 8 (analogous to the proximal and distal regions of the $\mathrm{Z}$ chromosome) show no $\mathrm{N}$-banding, whereas the telomeric regions do, it is generally possible to discriminate between these G-band-negative regions. However, in the $\mathrm{W}_{\mathrm{a}}$ and $\mathrm{W}_{\mathrm{b}}$ morphs novel $\mathrm{N}$-bands, not attributable to the postulated inversions, were observed. These may be due either to three break transpositions of $\mathrm{N}$-positive material or to localised changes in the banding properties associated with the structural rearrangements.

The results of the analysis are depicted as idiograms in Figure 4A, and critical G-band comparisons are shown in Figure $4 \mathrm{~B}$. In each case the minimum number of two break rearrangements is presumed and the expected position of each centromere ( $7 \mathrm{k}$ and $8 \mathrm{k}$ ) is shown.

The $\mathrm{W}_{\mathrm{b}}$ morph can be derived from the $\mathrm{Z}$ chromosome by two major, non-overlapping paracentric inversions and a minor, overlapping one. One of these large inversions incorporates bands 7-1 to 7-3; the other extends from the interstitial $\mathrm{G}$-negative region to below band $8-1$. Concurrently, the original $\mathrm{N}$-band-negative proximal region of chromosome 7 appears to have acquired an $\mathrm{N}$-positive reaction. The proposed subsequent minor inversion moves $8 \mathrm{k}$ to a slightly more proximal position.

The G-banding comparison of the $\mathrm{W}_{\mathrm{b}}$ and $\mathrm{W}_{\mathrm{d}}$ morphs show that despite the fact that they have their centromeres at opposite ends of the chromosome, there has been no change in the pattern of the intervening G-bands (Figs. 3, 4B). These data strongly suggest that there has been a repression of the activity of the centromere of chromosome
7 accompanied by a simultaneous activation of the centromere of chromosome 8 resulting in a functional centric transposition.

The $W_{f}$ morph observed in a single female (Table 1) can be derived from the $W_{d}$ variant by a small pericentric rearrangement (Fig. 4A, B). Since the quality of banding so far obtained on this morph is not optimal, this proposal requires confirmation. The derivation of the $W_{c}$ morph from $\mathrm{W}_{\mathrm{b}}$, on the other hand, is clearly by pericentric inversion (Fig. 4A). This is evident from the perfect homology of the long arm of $W_{c}$ with the $W_{b}$ chromosomes (Fig. $4 \mathrm{~B}$ ). The remaining variants of the $W$ chromosomes, $W_{a}$ and $\mathrm{W}_{\mathrm{e}}$, could not be directly related to the other morphs and are thus assumed to be derived independently from them. These two types of W chromosome show extensive homology in the long arms (Fig. 4B) and are clearly differentiated by a single pericentric inversion (Fig. $4 \mathrm{~A}$ ). However, the evolution of either type from the $\mathrm{Z}$ chromosome appears quite complex. While the relative G-band position of the $W_{\mathrm{a}}$ morph can be produced by one pericentric and two overlapping paracentric inversions of the $\mathrm{Z}$ chromosome (Fig. 4A), a three break rearrangement is required to explain the origin of the $\mathrm{N}$-band located terminally on the short arms (see $\mathrm{W}_{\mathrm{a}} \mathrm{N}$-banding, Fig. 3).

The geographic distribution of the variants of the $W$ chromosome (Fig. 5, Table 1) agrees with the proposed pattern of $\mathrm{W}$ chromosome evolution. Within the area sampled, the $\mathrm{W}_{\mathrm{a}}$ and $\mathrm{W}_{\mathrm{e}}$ variants are found in the northern region, and the remaining related $W$ chromosomes cluster in the southern area. Also, note that the closely related $\mathrm{W}_{\mathrm{b}}$ and $\mathrm{W}_{\mathrm{c}}$ morphs are sympatric at $\mathrm{Mt}$. Ebenezer. With this exception all the variation appears to be polytypic since the $\mathrm{W}$ chromosome is, by definition, never homozygous.

To date only the eastern half of the species range of 


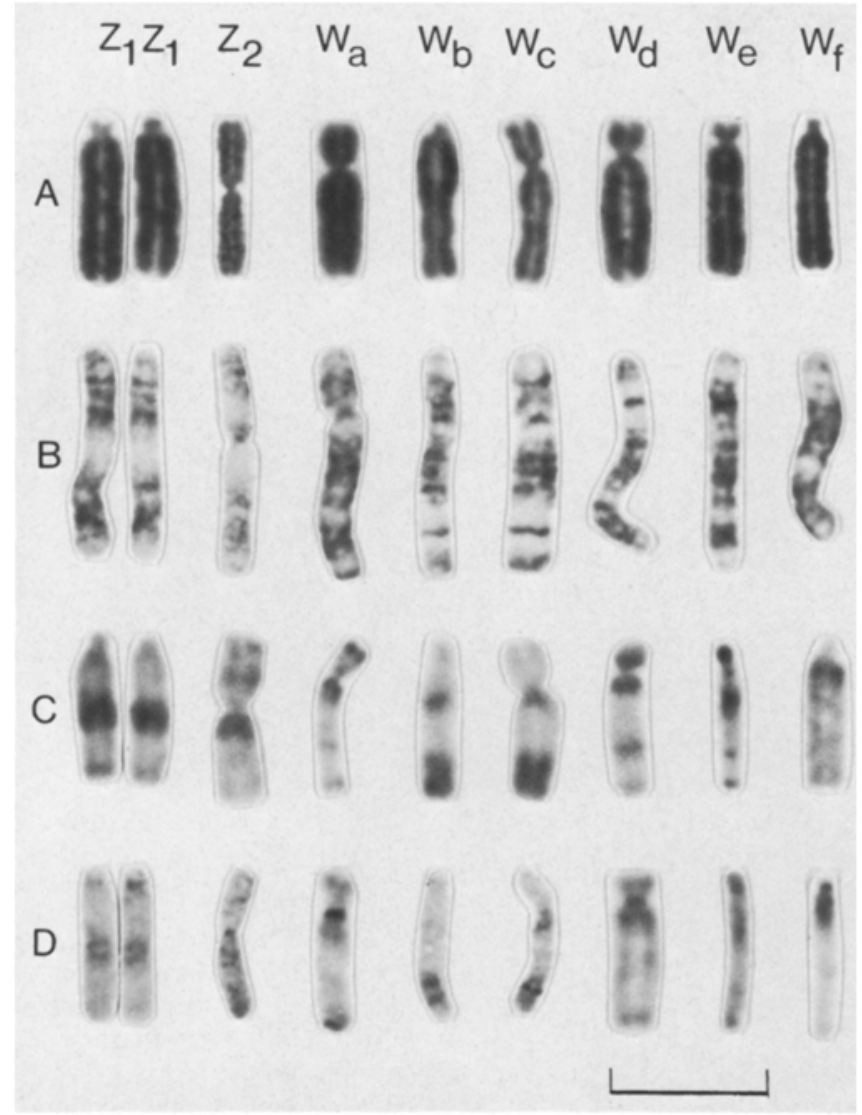

Fig. 3. Comparison of the various morphs of the $\mathrm{Z}$ and $\mathrm{W}$ chromosomes of $G$. purpurascens using conventional staining (A), G-banding (B), N-banding (C), and C-banding (D). Note the distinction between the distribution of $\mathrm{N}$-band material and darkly staining $\mathrm{C}$-band heterochromatin. In general the strongly $\mathrm{N}$-banded regions display a grey $\mathrm{C}$-banded appearance. Bar represents $8 \mu \mathrm{m}$

G. purpurascens has been examined, and it is possible that a detailed analysis of western populations might reveal further $\mathrm{W}$ chromosome variants.

\section{Meiotic analysis of the $Z Z$ bivalent}

Relative to the $\mathrm{W}$ chromosome, the $\mathrm{Z}$ chromosome of $G$. purpurascens is highly conserved. Since the survival of rearrangements of the $\mathrm{Z}$ chromosome could conceivably be restricted by free recombination along its length (White 1973) an analysis of chiasma frequency and position in the $\mathrm{ZZ}$ bivalent of males was undertaken.

The characteristic N-banding pattern of pair 1 in $G$. purpurascens allowed this bivalent to be unambiguously recognised at diakinesis and metaphase I of meiosis (Fig. 6A). In 254 spreads from a total of 13 males collected from widely separated localities the location of 484 chiasmata was scored as proximal, distal, or interstitial (Fig. 6 B). The former two classes encompass the distal and proximal quarter of the chromosome; interstitial chiasmata occupy the intervening half of the chromosome.

The analysis revealed extreme proximal-distal localisation with only $6 \%$ of the observed chiasmata lying interstitially. $91 \%$ of the bivalents had two chiasmata and the remainder had only one. The observed distribution of the chiasmata is detailed in Table 2.

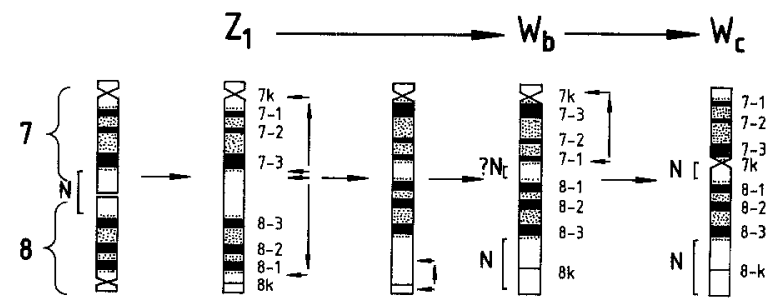

centric transposition (activate 8k, repress $7 k$ )
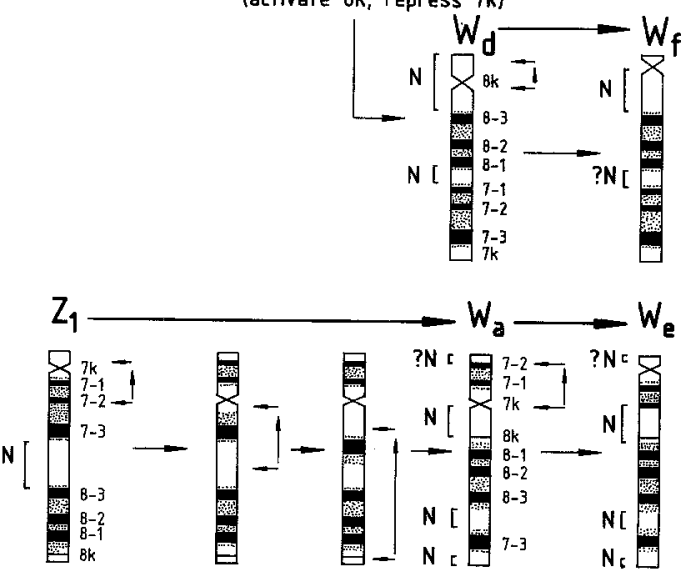

A
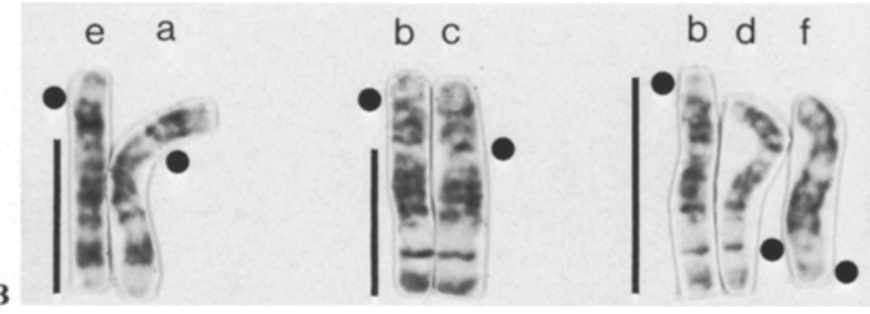

Fig. 4. A Rearrangements proposed to have produced the morphs of the W chromosome of $G$. purpurascens. At the extreme top left are the ancestral chromosomes 7 and 8 , which gave rise to the $Z$ chromosome. The numbers beside the $\mathrm{G}$-bands refer to the specific bands on chromosomes 7 and 8 . Also shown are the Nbanding regions of these chromosomes. ' $k$ ' denotes a centromere (see text). Two independent lineages of $\mathrm{W}$ chromosomes are evident from the banding analysis. B Critical G-band comparisons to indicate the region of homology between the various morphs $(a-f)$ of the $\mathrm{W}$ chromosome. The centric constriction was not evident in these elongate chromosomes and their position was determined in contracted metaphase preparations (see also Fig. 3). The vertical bars indicate the region of homology and the dots represent the position of the centromeres

\section{Discussion}

The fixed heterozygosity of 30 female $G$. purpurascens for chromosome 1 and the absence of these female-specific variants amongst the 40 males examined clearly demonstrates that a ZW sex chromosome system operates in this species. Both the nature of the rearrangements that lead to this differentiation and the extreme variability of the $W$ relative to the $\mathrm{Z}$ and the autosomes deserve further comment.

The derivation of the $Z$ chromosome by telomere-totelomere tandem fusion represents an unusual, although not unprecedented, mechanism of chromosomal change (Therman et al. 1974; Daniel 1979). Hsu et al. (1975) suggest that such a rearrangement will survive meiosis if one 


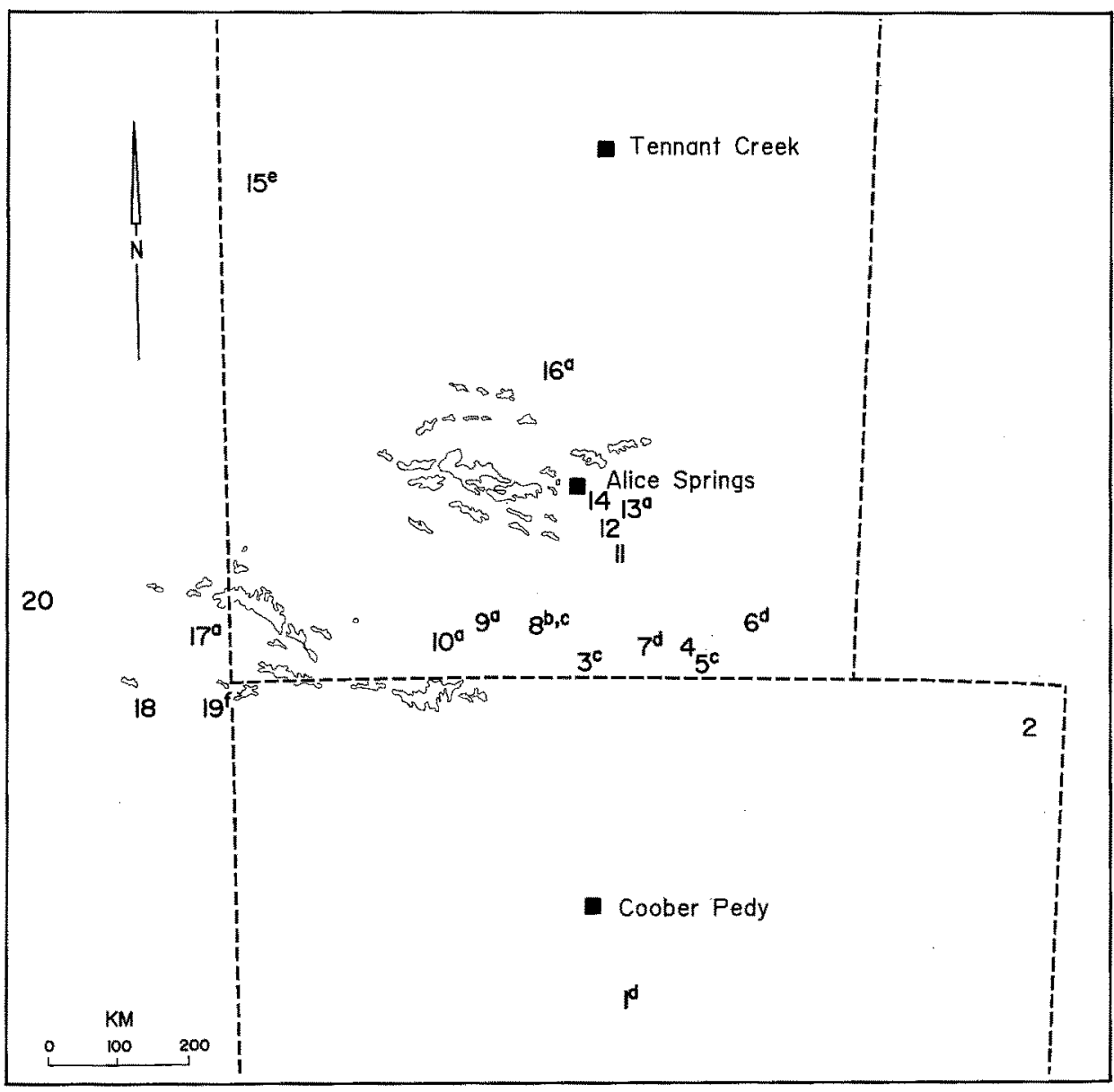

Fig. 5. Map of central Australia showing the distribution of the observed morphs of the $\mathrm{W}$ chromosome of $G$. purpurascens. The numbers refer to the localities given in Table 1. Note that the related $\mathrm{W}_{\mathrm{e}}$ and $\mathrm{W}_{\mathrm{a}}$ morphs occur in the north of the region sampled while the other variants cluster to the south of the two centromeres is either inactivated or lost. The $\mathrm{G}$-banding comparison of the $\mathrm{Z}$ chromosome of $G$. purpurascens with chromosomes 7 and 8 of the ancestral karyotype did not indicate any loss of chromatin. In fact a close inspection revealed a fine G-band distal to band 8-1 on the $\mathrm{Z}$ chromosome that corresponds precisely to the position of the centromere of chromosome 8 . Thus it would appear that this centromere became latent while the centromere of chromosome 7 remained active.

If this is indeed the case, then the potential exists for subsequent reactivation of the repressed centromere, as has been shown in isodicentric human X chromosomes (Therman et al. 1974). This reactivation, together with the simultaneous inactivation of the centromere of chromosome 7 , would account for the functional centric transposition that distinguishes the $\mathrm{b}$ and $\mathrm{d}$ morphs of the $\mathrm{W}$ chromosome. The remaining proposed rearrangements that lead to the observed variants of the $W$ chromosome are all paracentric or pericentric inverions.

Another striking feature of the analysis is the high level of variability of the $W$ chromosome relative to both the $\mathrm{Z}$ and the autosomes. Only a single variant of the $\mathrm{Z}$ chromosome and one autosomal polymorphism, involving a pericentric rearrangement of chromosome 4 , have been $\mathrm{ob}$ served in $G$. purpurascens, a situation which holds for the entire Gehyra variegata-punctata species complex (Moritz, in preparation). In these taxa intraracial variation consists mainly of restricted inversion polymorphism (King 1979; Moritz, in preparation) and C-band changes, while between races the G-band homology of chromosome arms is retained (Moritz, in preparation).

In reptiles generally the $\mathrm{W}$ chromosome is the most variable member of the karyotype. For example, in snakes the vast majority of reported examples of intraspecific variation involve this chromosome (Mengden 1981, 1983). Similarly, in an extensive survey of C-band variation in the gekkonid lizard Heteronotia binoei, chromosomal repatterning again predominates in the W chromosome (Moritz 1984).

What mechanisms can account for a high level of intraspecific variation in the $\mathrm{W}$ chromosome alone? Four non-exclusive hypotheses can be suggested to explain this observation:

(1) Structural rearrangements of the $\mathrm{Z}$ and autosomes are generally eliminated by selection against the unbalanced gametes generated as a result of recombination between the rearranged chromosomes (White 1973). In contrast, the virtual absence of recombination between the $\mathrm{Z}$ and $\mathrm{W}$ chromosomes would preclude such negative selection (Voronstov et al. 1980).

(2) The W chromosome is largely genetically inert, making it unlikely that rearrangements would disrupt the function of its component genes (Darlington 1958).

(3) By restricting recombination between the homologues the structural changes of the $\mathrm{W}$ chromosome promote the tight linkage of genes associated with sexual differentiation and so are selectively advantageous (Rothfels 1956; Ohno 1967).

(4) The presence of a sex determining locus in some 


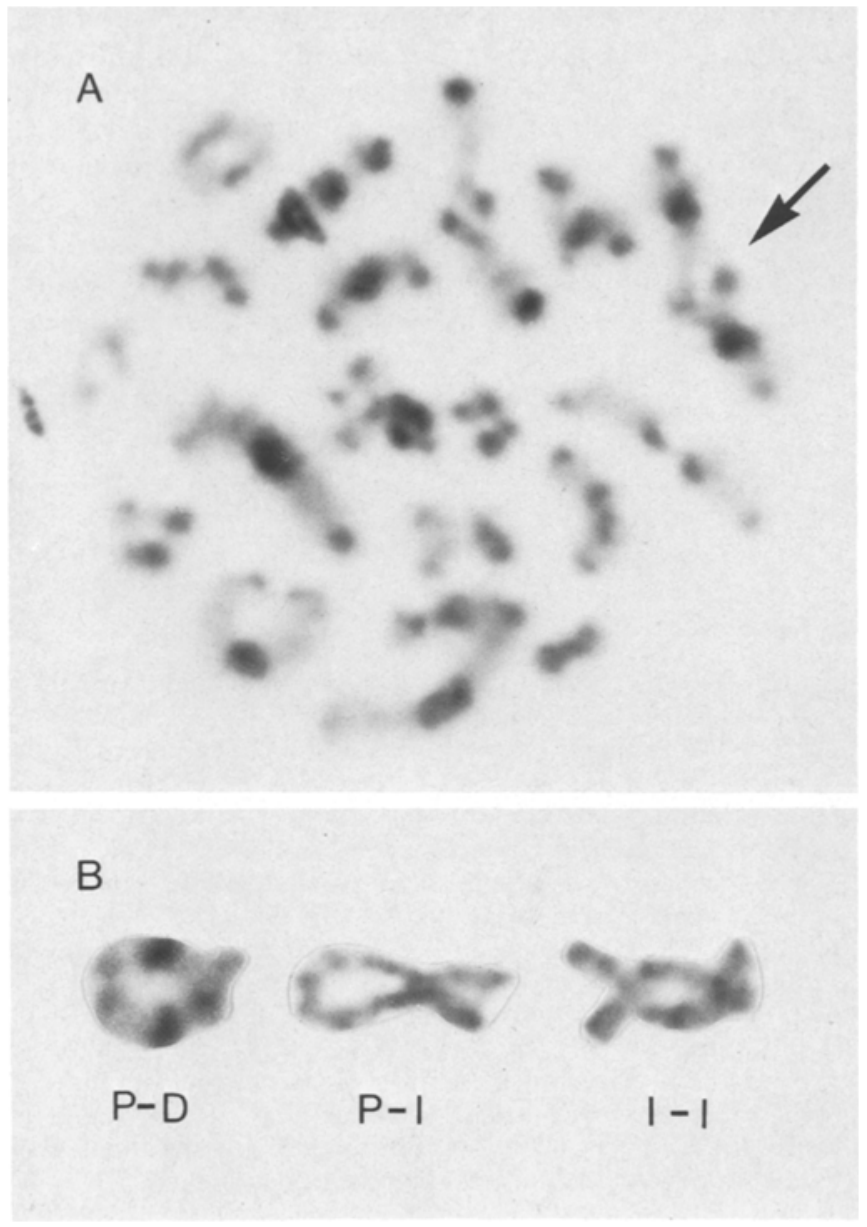

Fig. 6. A An $\mathrm{N}$-banded diakinesis from a male G. purpurascens. The $Z Z$ bivalent distinguished by the presence of the large interstitial N-band region is arrowed. $\mathbf{B}$ Individual $Z Z$ bivalents representing the proximal-distal $(P-D)$, proximal-interstitial $(P-I)$, and interstitial-interstitial $(I-I)$ location of chiasmata

Table 2. Observed distribution of chiasmata in the $\mathrm{ZZ}$ bivalent of 13 males of $G$. purpurascens from seven localities

\begin{tabular}{lcc}
\hline Chiasmata & $\begin{array}{l}\text { Proximal } \\
\text { and distal }\end{array}$ & Interstitial \\
\hline Single & 21 & 3 \\
Double & 434 & 26 \\
\hline
\end{tabular}

way increases the mutation rate of the $\mathrm{W}$ relative to its homologue, the $Z$, and to the autosomes.

The first hypothesis does not offer a convincing explanation for the variation in G. purpurascens. The extreme proximal-distal localisation of chiasmata in the ZZ bivalent of males would, by this argument, lead to the expectation of common paracentric inversions within the $\mathrm{Z}$ chromosome. No such variation was observed in the extensive G-banding analysis. Further, the presumption of recombination-induced selection against pericentric rearrangements is weakened by the fact that straight non-homologous pairing appears to be more general in pericentric rearrangement heterozygotes than inverted homologous pairing (John 1981).

The hypervariability of the $\mathrm{W}$ chromosome of snakes
(Mengden 1981), birds (Christidis, personal communication), and the Y chromosome of mammals (Voronstov et al. 1980 ) is conceivably attributable, at least in part, to the second hypothesis. Because these elements are largely heterochromatic and presumably have few transcribed genetic loci, rearrangements in them are less likely to be deleterious. Some caution is, however, needed before accepting this hypothesis since these chromosomes may not be totally inert. Unique sequences have been isolated from the human $Y$ chromosome (Bishop et al. 1983), and the generalisation that heterochromatin is devoid of active genes is certainly not tenable (Peacock et al. 1981).

In contrast to the situation in birds and mammals the W chromosomes of $G$. purpurascens and several other lizards (Bull 1978, Moritz 1984) are not highly heterochromatic. In lower vertebrates generally there is no evidence for the inactivation of W- (or Y-) linked genes (Ohno 1967; Elinson 1983). Therefore any selection against rearrangements that disrupt gene function would not be relaxed in this case.

The third hypothesis, which concerns selection for the restriction of recombination through chromosomal rearrangements, is one that needs to be treated with particular caution. Clearly, this form of selection could only operate if the initial sex-linkage group had already become established. In males of $G$. purpurascens, strong proximal-distal localisation of chiasmata is evident. If this situation occurred in the originally homomorphic females, then such a linkage group may have already been formed. This is, however, highly speculative since patterns of recombination are known to differ between males and females in several species (Fletcher and Hewitt 1980; Hayman 1981).

A relevant feature of the variation observed in the $\mathrm{W}$ chromosome of $G$. purpurascens is that each of the morphs most closely related to the $\mathrm{Z}$ chromosome $\left(\mathrm{W}_{\mathrm{a}}\right.$ and $\left.\mathrm{W}_{\mathrm{b}}\right)$ have been derived by multiple inversions that collectively involve the entire chromosome. As such, genetic exchange between the $\mathrm{W}$ and $\mathrm{Z}$ should be minimal. If the restriction of recombination by these inversions is in fact critical, then further sampling of the species range should not reveal the intermediate morphs between the $\mathrm{Z}$ and $\mathrm{W}_{\mathrm{a}}$ or $\mathrm{W}_{\mathrm{b}}$, which would be expected to be adaptively inferior (Fig. $4 \mathrm{~A}$ ).

On the basis of the available data the above arguments do not appear to wholely explain the hypervariability of the W chromosome of $G$. purpurascens unless, in addition, the mutation rate is higher for this element. The increased mutability of the ancestral homomorphic sex chromosomes would then be due to the presence of the sex-determining locus.

A possible molecular mechanism for such an increased mutation rate is provided by recent studies on the properties of transposable elements. Transposons are undoubtedly capable of inducing a high frequency of gross chromosomal rearrangements (McClintock 1978; Shapiro and Cordell 1982), and if these elements are associated with the sexdetermining locus as postulated by Green (1980) and Hickey (1982), they may account for the variable nature of sex chromosomes. A similar suggestion was made by Jones and Singh (1982) to account for the presence of the Bkm satellite in sex-reversed mice (XX; Sxr/- males). This sequence, for which they have proposed a key role in sex determination, appears to share some of the properties of a transposable element. It is therefore plausible that the sex-determining region is flanked by transposable elements, 
which would enable these loci to move within and between chromosomes.

The movement of sex-determining genes between chromosomes is compatible with the observation of different non-homologous chromosomes being involved in sex chromosome differentiation in amphibians (Mengden 1981; Schmid 1980; Schmid et al. 1983) and turtles (Sites et al. 1979; Carr and Bickham 1981).

However, with regard to the postulated induction of chromosome rearrangements in Gehyra the transposition must for two reasons be primarily intrachromosomal, a behaviour pattern that is known to characterise the $M_{p}$ element of Zea mays (reviewed in Federoff 1983). First, the proposed increased mutability is in evidence only on the $\mathrm{W}$ chromosome in this species. Second, there are indications that within this genus it is always chromosome 7 that functions as a sex chromosome. In central Australian population of $G$. nana with $2 n=44$ a sex-linked polymorphism for the presence of an additional NOR on chromosome 7 has been observed (Moritz, in preparation). Also in the related Gehyra australis, King (1977) described a sex-correlated heteromorphism of pair 1 of the $40 \mathrm{C}$ chromosome race of G. australis. This cytotype is presumed by King (1983) to have arisen from the $42 \mathrm{~A}$ race by the loss of a small acrocentric element possibly as a result of tandem fusion. The heteromorphic pair 1 in this case has a broad interstitial C-band, which is unusual in Gehyra, suggesting that the $\mathrm{Z}$ chromosome of this species may be derived from a tandem fusion of chromosome 7 to a small acrocentric chromosome. If this is the case, then the location of the sex-determining genes on chromosome 7 may be shared between $G$. australis, G. nana, and G. purpurascens.

The principle attraction of the transposon-induced differential mutation hypothesis to explain highly variable $\mathrm{W}$ chromosomes is that, in contrast to the alternatives, it is testable. A critical experiment would be to obtain a library of cloned insertion sequences from female $G$. purpurascens and test for the occurrence of an element that hybridised with the DNA of females but not males. A positive result would demonstrate that a transposable element was located exclusively on the $\mathrm{W}$ chromosome.

While the precise molecular mechanism that allows for the extreme variability of the W chromosome in G. purpurascens remains to be elucidated, this is clearly a situation where considerable structural differentiation has occurred in the absence of either the amplification of, or the spread of, C-band heterochromatin. Previous examples of alterations of sex chromosomal morphology without C-band change appear to involve only single and small rearrangements (Bull 1978, Kezer and Sessions 1979; Mengden and Stock 1980). The karyotypic data presented for G. purpurascens demonstrate that with continued structural differentiation little homology will remain between the $\mathrm{W}$ and the $\mathrm{Z}$ elements. Indeed, the complexity of the rearrangements in this species is analogous to the sex-linked inversion systems of some Diptera (Rothfels 1956; Bedo 1977; Post 1982).

As an alternative to differentiation of the sex chromosomes by structural rearrangements it has been proposed that the initial stage involves heterochromatinisation (Ray Chaudhuri et al. 1971; Singh et al. 1976, 1980). This, it has been argued, has been achieved by the tandem duplication and spread of satellite DNAs on the heteromorphic sex chromosome. While euchromatin-heterochromatin trans- formation and heterochromatin addition does appear to be involved in the initial differentiation of sex chromosomes in some cases (e.g. King 1977; Schmid 1980; Schmid et al. 1979, 1983; Mengden 1981; Sessions 1982), it is, as pointed out by Mengden (1981), clearly not a prerequisite for the evolution of highly differentiated sex chromosomes.

Acknowledgements. I am extremely grateful to Mr. D. Lindemayer, Mr. R. Martin and Dr. T. Schwaner for assistance in collecting specimens. I thank Drs. D. Coates, B. John, M. King, G. Mengden, D. Shaw, and G. Peters and Mr. L. Christidis and Mr. S. Donnellan for valuable discussion and comments on the manuscript, and $G$. Brown for illustration. This study was supported by The Australian National University, a Commonwealth Postgraduate Research Award, and a grant from the National Geographic Society.

\section{References}

Bedo DG (1977) Cytogenetics and evolution of Simulium ornatipes Skuse (Diptera: Simulidae). Chromosoma 64:37-65

Bickham JW (in press) Patterns of modes of chromosomal evolution in reptiles. In: Sharma AK, Sharma A (eds) Chromosomes in evolution of eukaryotic groups. CRC Press Inc., Boca Raton

Bishop CE, Guellaen G, Geldwerth D, Voss R, Fellous M, Weissenback J (1983) Single copy DNA sequences specific for the human Y chromosome. Nature 303:831-832

Bull JJ (1978) Sex chromosome differentiation: an intermediate stage in a lizard. Can J Genet Cytol 20:205-209

Bull JJ (1980) Sex determination in reptiles. Q Rev Biol 55:3-21

Carr JL, Bickham JW (1981) Sex chromosomes of the Asian black pond turtle, Siebenrockiella crassicollis (Testudines: Emydidae). Cytogenet Cell Genet 31:178-183

Daniel A (1979) Single Cd band in dicentric translocations with one suppressed centromere. Hum Genet 48:85-92

Darlington CD (1958) The evolution of genetic systems 2nd Ed. Basic Books, New York, p 240

Elinson RP (1983) Inheritance and expression of a sex-linked enzyme in the frog Rana pipiens. Biochem Genet $21: 435-443$

Fedoroff NV (1983) Controlling elements in maize. In: Shapiro JA (ed) Mobile genetic elements. Academic Press, New York, pp $1-63$

Fletcher HL, Hewitt GM (1980) A comparison of chiasma frequency and distribution between sexes in three species of grasshoppers. Chromosoma 77:129-144

Gerlach WL (1977) N-banded karyotype of wheat species. Chromosoma 62:49-56

Green M (1980) Transposable elements in Drosophila and other Diptera. Ann Rev Genet 14:109-120

Hayman DL (1981) Components of genetic systems in mammals. In: Atchley WR, Woodruff DS (eds) Evolution and speciation. Cambridge Univ Press, Cambridge, pp 52-65

Hickey DA (1982) Selfish DNA: a sexually transmitted nuclear parasite. Genetics 101:519-531

Hsu TC, Pathak S, Chen TR (1975) The possibility of latent centromeres and a proposed nomenclature system for total chromosome and whole arm translocations. Cytogenet Cell Genet 15:41-49

John B (1981) Chromosome change and evolution change: a critique. In: Atchley WR, Woodruff DW (eds) Evolution and speciation. Cambridge Univ Press. Cambridge, pp 23-51

John B, Miklos GLG (1979) Functional aspects of satellite DNA and heterochromatin. Int Rev Cytol 58:1-114

Jones KW, Singh L (1982) Conserved sex-associated repeated DNA sequences in vertebrates. In: Dover G, Flavell RB (eds) Genome evolution. Academic Press London, New York pp 135-154

Kezer J, Sessions SK (1979) Chromosome variation in the Plethodontid salamander Aneides ferreus. Chromosoma 71:65-80

King M (1977) The evolution of sex chromosomes in lizards pp 
55-60. In: Calaby J, Tyndale H, Biscoe (eds) Evolution and Reproduction. Australian Academy of Science, pp 55-60

King M (1979) Karyotypic evolution in Gehyra (Gekkonidae:Reptilia) I. The Gehyra variegata punctata complex. Aust $J$ Zool 27:373-393

King M (1983) Karyotypic evolution in Gehyra (Gekkonidae: Reptilia) III. The Gehyra australis complex. Aust $J$ Zool 31:723-741

King M, Rofe R (1976) Karyotypic variation in the Australian gecko Phyllodactylus marmoratus (Gray) (Gekkonidae: Reptilia). Chromosoma 54:75-87

Leversha M, Sinfield C, Webb GC (1980) Rapid and reliable method for the $\mathrm{G}$ and $\mathrm{C}$ banding of human and other mammalian chromosomes. Aust J Med Sci 1:139-143

McClintock B (1978) Mechanisms that rapidly reorganise the genome. Stadler Symp 10:25-47

Mengden GA (1981) Linear differentiation of the C-band pattern of the W chromosome in snakes and birds. Chromosoma $83: 275-287$

Mengden GA (1983) Chromosomal evolution of elapid snakes. $\mathrm{PhD}$ Thesis, The Australian National University

Mengden GA, Stock AD (1980) Chromosomal evolution in Serpentes; a comparison of $\mathrm{G}$ and $\mathrm{C}$ chromosome banding patterns of some colubrid and boid genera. Chromosoma 79:53-64

Moritz C (1984) The origin and evolution of parthenogenesis in Heteronotia binoei (Gekkonidae). I. Chromosome banding studies. Chromosoma 89:151-162

Ohno S (1967) Sex chromosomes and sex-linked genes. Springer, Berlin Heidelberg New York, p 174

Olert J (1979) Interphase studies with a simplified method of silver staining of nucleoli. Experientia 35:283-285

Peacock WJ, Dennis ES, Hilliker AJ, Pryor AJ (1981) Differentiation of heterochromatin. In: Atchley WR, Woodruff DS (eds) Evolution and speciation. Cambridge Univ Press Cambridge, pp $78-100$

Post RJ (1982) Sex-linked inversions in black flies (Diptera: Simuliidae). Heredity 48:85-93

Ray Chaudhuri SP, Singh L, Sharma T (1971) Evolution of sex chromosomes and formation of $\mathrm{W}$ chromatin in snakes. Chromosoma 33:239-251
Rothfels KH (1956) Black flies: siblings, sex and species grouping. J Hered 47:113-122

Schempp W, Schmid M (1981) Chromosome banding in amphibia. VI. BrdU replication patterns in Anura and demonstration of $\mathrm{XX} / \mathrm{XY}$ sex chromosomes in Rana esculenta. Chromosoma $83: 697-710$

Schmid M (1980) Chromosome banding in amphibia. V. Highly differentiated $\mathrm{ZW} / \mathrm{ZZ}$ sex chromosomes and exceptional genome size in Pyxicephalus adspersus (Anura:Ranidae). Chromosoma 80:69-96

Schmid M, Olert J, Klett C (1979) Chromosome banding in amphibia III. Sex chromosomes in Triturus. Chromosoma $71: 29-55$

Schmid M, Haaf T, Geile B, Sims S (1983) Chromosome banding in amphibia VIII. An unusual XY/XX sex chromosome system in Gastrotheca riobambae (Anura, Hylidae). Chromosoma $88: 69-82$

Sessions SK (1982) Cytogenetics of diploid and triploid salamanders of the Ambystoma jeffersonium complex. Chromosoma $84: 599-621$

Shapiro JA, Cordell B (1982) Eukaryotic mobile and repeated genetic elements. Biol Cell 43:31-54

Singh L, Purdom IF, Jones KW (1976) Satellite DNA and evolution of sex chromosomes. Chromosoma 59:43-62

Singh L, Purdom IF, Jones KW (1980) Sex chromosome associated satellite DNA: Evolution and conservation. Chromosoma 79:137-157

Sites JW, Bickham JW, Haiduk MW (1979) Derived X chromosome in the turtle genus Staurotypus. Science 206:1410-1412

Therman E, Sarto GE, Patau K (1974) Apparently isodicentric but functionally monocentric $X$ chromosome in man. Ann J Hum Genet 26:83-92

Voronstov NN, Lyapunova EA, Borissov YuM, Dougal VE (1980) Variability in sex chromosomes in mammals. Genetica 52/53: 361-372

White MJD (1973) Animal cytology and evolution. Cambridge Univ Press, London New York Melbourne, p 784

Received February 1, 1984 / in revised form March 26, 1984

Accepted by B. John 